\title{
LA DÉCADA DE LA VIOLENCIA EN PERÚ. UTOPIA ANDINA, CAMPESINADO Y CRISIS DE LA ANTROPOLOGÍA ANDINA
}

\author{
The Decade of Violence in Peru.
}

\author{
Andean Utopia, Peasantry and the Crisis of Andean Anthropology
}

\section{PABLO SANDOVAL*}

Fecha de recepción: 28 de mayo de 2021 - Fecha de aprobación: 03 de octubre de 2021

\section{Resumen:}

Este artículo reconstruye dos debates producidos en la década de 1980 en la comunidad de antropología peruana, donde se compartía una agenda común: la reflexión sobre la identidad y el redescubrimiento del "mundo andino". Antropólogos e historiadores se vieron atraídos a participar en los debates políticos contemporáneos buscando encontrar la vigencia del racismo y la violencia de origen colonial en las prácticas de discriminación cotidianas en ese momento. Pese a las diferencias de perspectivas esta discusión sobre lo "andino" tomó dos caminos específicos: el debate sobre el Informe Uchuraccay liderado por Mario Vargas Llosa y el de la propuesta sobre la "utopía andina" protagonizado principalmente por Alberto Flores Galindo.

Palabras clave: conflicto armado; Sendero Luminoso; antropología andina; Mario Vargas Llosa, Alberto Flores Galindo.

\section{Abstract:}

This article reconstructs two debates that took place in the 1980s in the Peruvian anthropology community, where a common agenda was shared: the reflection on identity and the rediscovery of the "Andean world". Anthropologists and historians were attracted to participate in contemporary political debates seeking to find the validity of racism and violence of colonial origin in the everyday practices of discrimination in the 1980s. Despite the differences in perspectives, this discussion on the "Andean" took two specific paths: the debate on the Uchuraccay Report led by Mario Vargas Llosa; and the one led mainly by Alberto Flores Galindo around his proposal of the "Andean utopia".

Keywords: armed conflict; Shining Path; Andean anthropology; Mario Vargas Llosa, Alberto Flores Galindo.

\footnotetext{
* Dr. en Historia. Antropólogo. Escuela de Antropología, Universidad Mayor de San Marcos, Lima, Perú. Correo-e:
} psandovall@unmsm.edu.pe 


\section{Introducción}

La década de 1980 redefinió la forma en que las ciencias sociales peruanas interpretaron las rutas culturales que tomaron las poblaciones campesinas andinas. El proceso de modernización rural que buscó impulsar la reforma agraria del gobierno militar (1968-1980) tomó rumbos inesperados, sorprendido por la inesperada irrupción armada de Sendero Luminoso en 1980. Justo en esos años se replantea el antiguo "problema indígena" impulsado décadas antes por José Carlos Mariátegui y la antropología andinista. Las fronteras interétnicas entre indios, mistis y criollos se vuelven cada vez más porosas y, en particular, se va desdibujando lo que en aquel momento se interpretaba, desde cierta mirada antropológica, como la oposición cultural entre "Andes" y "Occidente". En este nuevo escenario se terminó de modificar el rol asignado a la antropología de una disciplina encargada de investigar las dimensiones "tradicionales" de la "cultura andina" y se replantearon los lentes interpretativos de análisis sobre los pueblos indígenas.

Quizá el mayor avance en la compresión de los Andes provino de la historia social andina escrita esencialmente por investigadores anglosajones. Tras la pregunta de cuál era el significado histórico de la cultura y la tradición andina, esta historiografía buscó distanciarse de la práctica etnohistórica y etnográfica anterior, pues al carecer de una adecuada dimensión diacrónica con frecuencia alentaba imágenes estáticas de "continuidad andina" como opuestas a las dinámicas abiertas por el mercado y la política global. En la búsqueda de una perspectiva temporal pertinente, esta nueva historia social propuso una radical reconceptualización de las poblaciones andinas situando las experiencias indígenas y campesinas en la intersección de la historia, la economía política y la cultura, recurriendo muchas veces a conceptos y métodos antropológicos (Thurner, 1998).

El objetivo de este enfoque era cerrar las brechas entre la etnohistoria, la etnografía andina y la historia económica ${ }^{1}$ reinsertando a los Andes en una dinámica histórica que sí tomara en cuenta las agencias, prácticas e ideologías políticas campesinas. Al intentar un mayor realismo histórico, fue superando el estereotipo de "lo andino" como un núcleo cultural excluyente y estáticamente durable en medio de los tumultuosos cambios políticos y económicos del siglo XX. Durante buena parte de la década de 1970, la etnología andina de corte estructuralista se mantuvo aislada debido "a su único propósito de búsqueda de propiedades ecológicas y culturales andinas sin paralelo, con frecuencia analizadas al margen de procesos históricos más amplios" (Larson, 2000; Salomón, 1982). Algo parecido ocurría con la etnohistoria que, según Pablo Macera, representaba sin duda una crítica al establishment historiográfico hispanista, aunque no por eso dejó de ser menos conservador: "[había] un radicalismo pasadista que consistía en protestar contra los abusos del poder colonial en los siglos XVI-XVIII, pero sin decir nada, en cambio, acerca de los abusos del poder en el siglo XX" (Macera, 1977, p. 21).

Ello contrastaba con las preguntas que se formulaban los científicos sociales marxistas, que pocas veces prestaron atención a los temas étnicos y culturales, preocupados, más bien, por el carácter económico del comportamiento del campesinado en el marco del modo de producción capitalista o en sus movilizaciones políticas supuestamente revolucionarias ${ }^{2}$. Esta brecha 
de perspectivas se puso claramente de manifiesto en dos conferencias académicas internacionales, realizadas en 1973 y 1974, como lo reseña la historiadora Brooke Larson:

\begin{abstract}
Mientras los antropólogos andinos se reunían en Toronto en 1973 para descifrar las prácticas andinas de parentesco y los verdaderos parámetros conceptuales del ayllu, un año después los marxistas latinoamericanos se reunían en lo que se convertiría en el panel de debate histórico sobre los modos de producción y el lugar que ocupó el campesinado en la transición al capitalismo $(2000, \text { p. } 9)^{3}$.
\end{abstract}

El propósito de esta nueva perspectiva era extender el estudio de la historia andina más allá de $1532^{4}$. No se trataba solo de proponer que la "resistencia andina" encarnaba procesos muchos más complejos que la mera defensa estática de un núcleo cultural andino duradero; se trataba, ahora, de otorgarle a las colectividades andinas "papeles históricos activos que fluctuaran entre la cooperación y la intransigente rebelión" (Salomón, 1991, p. 10). El objetivo era

[...] salvar la distancia tradicional entre los etnohistoriadores, que insisten en la durabilidad de las normas culturales e instituciones andinas, y los historiadores económicos que analizan el poder de transformación del mercado y el estado durante los periodos colonial y republicano. [De lo que se trata] es que se trascienda el enfoque dicotomizado de la sociedad rural andina. (Harris, Larson \& Tandeter, 1987, p. 21)

En el Perú, sin embargo, estos cambios asumieron una tonalidad nacional distinta al de sus colegas extranjeros. Historiadores, etnohistoriadores y arqueólogos marxistas peruanos que trabajaban en el remoto pasado prehispánico y colonial se vieron atraídos a participar en los debates políticos contemporáneos buscando encontrar la vigencia del racismo y la opresión colonial en las prácticas de discriminación cotidianas de la década de 1980. Pese a sus diferencias o matices de perspectivas, todos compartían una agenda común: la reflexión sobre la identidad y el redescubrimiento del "mundo andino" en pleno contexto del conflicto armado interno y de crisis del modelo económico 5 .

Esta discusión sobre el "mundo andino" tomó dos caminos específicos: el llamado debate sobre el Informe del caso de la matanza de periodistas en la comunidad de Uchuraccay; y la que protagonizó el historiador Alberto Flores Galindo alrededor de su propuesta sobre la "utopía andina".

\section{Modernidad, Occidente y tiempo en la comunidad de Uchuraccay}

El debate del caso Uchuraccay fue protagonizado a propósito del Informe elaborado por una comisión investigadora presidida por el escritor Mario Vargas Llosa. Esta comisión, nombrada el 2 de febrero de 1983 por el presidente Fernando Belaúnde (1980-1985), tuvo como misión investigar la matanza de ocho periodistas ocurrida el 26 de enero de 1983 en la comunidad indígena de Uchuraccay, en las zonas altas de Huanta (Ayacucho) $^{6}$. Los periodistas habían sido asesinados en Uchuraccay cuando trataban de cubrir la noticia de la muerte de siete militantes senderistas en las comunidades vecinas de Huaychao y Macabamba, pocos días antes, el 21 de enero. Su muerte se produjo en medio de una cruenta confrontación entre militares del ejército y las columnas armadas de Sendero Luminoso, en la zona rural de la provincia de Huanta. 
En dicho informe, presentado en marzo de ese mismo año, participaron como asesores cuatro destacados antropólogos, especializados en el estudio de las comunidades andinas: Fernando Fuenzalida, Juan Ossio, Luis Millones y Ricardo Valderrama?. En sus argumentos y conclusiones se recae sin reparos en las esencializaciones más flagrantes al construir la imagen etnográfica de los comuneros quechuas de Uchuraccay desde la alteridad radical, es decir, como culturalmente "Otros", situándolos por fuera de la temporalidad cronológica de la modernidad y como no contemporáneos del "presente nacional".

La Comisión Investigadora partía de la siguiente pregunta: ¿cómo explicar, lo más honestamente posible, estos trágicos y confusos sucesos ocurridos en una zona rural tan alejada de la capital y donde, al parecer, aún prevalecía entre los campesinos una persistente cultura arcaica y tradicional? En una entrevista de marzo de 1983, el propio Vargas Llosa definió así las dos temporalidades históricas en que se hallaban inmersos los comuneros de Uchuraccay. Entre el "Perú real" de los pobladores rurales y el "Perú oficial" de los ciudadanos modernos:

El que haya un país real completamente separado del país oficial es, por supuesto, el gran problema peruano. Que al mismo tiempo vivan en el país hombres que participan del siglo $\mathrm{XX}$ y hombres como los comuneros de Uchuraccay y de todas las comunidades iquichanas que viven en el siglo XIX, para no decir en el siglo $X V I I$. Esa enorme distancia que hay entre los dos Perú está detrás de la tragedia que acabamos de investigar. (Vargas Llosa, 1983b, p. 18, énfasis mío)

El relato central del Informe, escrito por el propio Vargas Llosa, se esfuerza en describir a los comuneros de Uchuraccay como opacados por el atraso histórico y la miseria de su condición de excluidos. En su empeño por elaborar una explicación al asesinato de los periodistas, este señala:

La Comisión cree que para no quedarse en una mera descripción superficial de lo ocurrido es necesario tener en cuenta [que] las comunidades de las punas de Huanta representan acaso el conglomerado humano más miserable y desvalido. Sin agua, ni luz, sin atención médica, sin caminos que los enlacen con el resto del país, sin ninguna clase de asistencia técnica o servicio social, en las altas tierras inhóspitas de la cordillera donde han vivido aislados y olvidados desde los tiempos prehispánicos, los iquichanos han conocido de la cultura occidental, desde que se instaló la República, solo las expresiones más odiosas. (Vargas Llosa 1983b, pp. 34-35)

¿Atrasados, tradicionales, reacios al cambio? Tales parecen ser las coordenadas intelectuales de Vargas Llosa, pues, en su opinión, los comuneros de Uchuraccay no habían logrado entender bien las nociones modernas de superación y progreso. Les había sido muy difícil concebir la idea de futuro, pues desde tiempos inmemoriales "no han experimentado mejora alguna en sus condiciones de vida", sino, más bien, han vivido en "un prolongado estancamiento con periódicos retrocesos" (Vargas Llosa, 1983a, p. 35). Más que partícipes de una temporalidad moderna, los comuneros de Uchuraccay vivían atrapados en una escala temporal arcaica, que les impedía el acceso y la plena conciencia de los beneficios de Occidente ${ }^{8}$.

En esta condición de alteridad ontológica, la modernidad le era ajena a los comuneros de Uchuraccay y los colocaba en una distancia casi insalvable entre Occidente y lo indígena. Esto le permitía a Vargas Llosa preguntarse, incluso, si realmente los campesinos de Uchuraccay (finalmente, los autores del asesinato de los periodistas) eran los reales culpables de este trágico acontecimiento. ¿Eran capaces los 
campesinos de hacer razonamientos jurídicos sobre la Constitución? ¿No eran, acaso, limitadas sus posibilidades de entender la diferencia entre la ley y la costumbre? No hay que olvidar, prosigue Vargas Llosa, que estamos "ante hombres que viven en las condiciones de primitivismo, aislamiento y abandono" (Vargas Llosa, 1983a, pp. 33-34):

\begin{abstract}
¿Tiene el Perú oficial el derecho de reclamar de estos hombres, a los que con su olvido e incuria mantuvo en el marasmo y el atraso, un comportamiento idéntico al de los peruanos que, pobres o ricos, andinos o costeños, rurales o citadinos, participan realmente de la modernidad y se rigen por leyes, ritos, usos y costumbres que desconocen (o difícilmente podrían entender) los iquichanos?. (Vargas Llosa, 1983b p. 36)
\end{abstract}

Exculpados retóricamente por su "no modernidad", el Informe causó una fuerte polémica pues encontraba una responsabilidad directa en los campesinos como autores de la masacre (Vargas Llosa, 1983a). En respuesta, el beligerante periodismo de izquierda, principalmente El Diario de Marka y La República, y algunos antropólogos de esa tendencia, sostenían lo contrario: que los autores de la masacre, o por lo menos sus instigadores, habían sido las fuerzas armadas.

Los campesinos, afirmaba el antropólogo vinculado a la izquierda, Rodrigo Montoya, quizá el más férreo opositor a las conclusiones de la Comisión, no eran capaces de semejante atrocidad, pues el ejercicio de la violencia entre las comunidades andinas estaba profundamente regulado por prácticas culturales ancestrales y respondía a complejos procesos rituales. Más que reacciones imprevistas, sostenía Montoya, la violencia en los Andes solo se practicaba en momentos de decisión comunales extraordinarios y en situaciones culturales límites muy precisas. Como muestra de que las fuerzas del orden estaban involucradas en la masacre, Montoya señalaba que los campesinos de Uchuraccay jamás enterrarían desnudos a los muertos (como ocurrió con los periodistas), pues primero debían cumplir ciertos protocolos rituales: por ejemplo, vestirlos con las mejores prendas, ya que el reencuentro del hombre con la tierra, que supone el entierro y la muerte, debía protegerlos de "los zorros, perros, gavilanes, halcones y cóndores" (Montoya, 1983a, p. $11)^{9}$. Y añade:

Si en siglos de historia, los campesinos solos jamás masacraron a desconocidos, habría que explicar en qué condiciones precisas y por qué los campesinos hicieron solos esta masacre, si hay razones científicamente serias para afirmar que los campesinos no han actuado solos, es inevitable admitir la hipótesis de la presencia de otras personas del exterior. Infiltrar al enemigo es un viejísimo principio de la guerra. (Montoya, 1983a, p.14)

La influencia externa (la infiltración) aparece como un argumento para explicar el comportamiento campesino en estos trágicos sucesos. No hay agencia campesina. Aunque en orillas ideológicas opuestas, el asesor legal de la Comisión, el jurista liberal Fernando de Trazegnies, apuntaba en la misma dirección. En su informe señalaba que cuando los comuneros de Uchuraccay declararon a la Comisión, lo hicieron "como una tribu o nación que decide ratificar su alianza con otra nación o tribu que se encuentra envuelta en una guerra" (De Trazegnies, 1983, p. 145). Los campesinos de Uchuraccay no tenían una clara conciencia del Estado peruano. Todo lo contrario, "viven intensamente su propia identidad étnica constituyendo verdaderas nacionalidades dentro de la Nación" (De Trazegnies, 1983, p. 152). 
Un esencialismo versus otro, de derecha y de izquierda, parecía entonces paralizar cualquier explicación precisa de lo ocurrido.

En medio de una abierta controversia política entre el gobierno y una férrea izquierda en la oposición, la Comisión Investigadora poco pudo hacer para convencer a la opinión pública de su conclusión final: que los comuneros, por un error fatal, confundieron a los ocho periodistas con una columna armada de Sendero Luminoso y les dieron una muerte violenta en la propia comunidad, para luego enterrarlos apresuradamente, fuera de la misma.

El asunto crucial fue el argumento antropológico que sustentaba estas conclusiones: los campesinos cometieron estos terribles actos debido a su postergación y subordinación cultural, al estar inevitablemente atrapados en las enormes distancias materiales y emocionales que los separaban del "Perú oficial". Juan Ossio y Fernando Fuenzalida, asesores de la comisión y que, junto a Vargas Llosa, visitaron oficialmente la comunidad el 12 de febrero de 1983, describen así el uso cultural de la tecnología moderna por parte de los comuneros de Uchuraccay:

No sorprende que muchos comuneros posean tocadiscos, linternas y otros artefactos eléctricos, ni que productos manufacturados como fideos, azúcar, alcohol, sean ahora parte de sus necesidades. Aunque, ciertamente, artefactos más sofisticados, como teleobjetivos o periódicos no entran en su horizonte experiencial. La existencia de comunidades totalmente ajenas al mundo industrial es en la actualidad una utopía, sin embargo, esto tampoco quiere decir que, por poseer unos cuantos objetos de aquel mundo, la integración plena se ha alcanzado. (Ossio \& Fuenzalida, 1983, p. 54)

Para Ossio \& Fuenzalida la ideología y las creencias locales no permitían definir con clari- dad la idea de "enemigo" en términos políticos. Lo más plausible era que los campesinos de Uchuraccay, en su confusión, identificaron a los senderistas y a los periodistas "con fuerzas mágicas del mal" (Ossio \& Fuenzalida, 1983, p. 76). Pero no solo eso, pues agregaban: "Es evidente que no pertenece a la experiencia cultural inmediata de estos campesinos la noción de 'periodista'” (Ossio \& Fuenzalida, 1983, p. 76).

¿Dónde encontrar, entonces, la explicación final a este "desencuentro ontológico"? La muerte lamentable de estos ocho periodistas debía ser atribuida "a una reacción de pánico de los comuneros", totalmente comprensible para Ossio \& Fuenzalida, ya que se hallaban en medio de un contexto local y regional de violencia que se prestaba a graves confusiones. No hay que olvidar, señalaban los antropólogos, que los campesinos de las alturas de Huanta se encontraban en la absoluta imposibilidad, psicológica, social y cultural, de "percibir en las mismas categorías legales, políticas, militares, éticas o religiosas que un hombre de la costa modernizada" (Ossio \& Fuenzalida, 1983, pp. 76-77).

En consecuencia, la muerte de los ocho periodistas "que ahora lamenta todo el país" es la prueba más contundente de que aún se arrastraban, "luego de 400 años de contactos entre la cultura europea y la cultura andina", problemas de integración y que "todavía no ha sido posible el desarrollo de un verdadero diálogo" (Ossio \& Fuenzalida, 1983, p. 77). "Si alguien tiene la culpa de este trágico malentendido no son los campesinos. Somos nosotros mismos", declararía Fuenzalida al diario El Comercio en junio de 1983 (Fuenzalida, 1983a, p. 7) ${ }^{10}$.

A todo esto, ¿dónde quedaba, finalmente, el compromiso de la antropología con el destino 
de estos campesinos, atrapados, sin saberlo, entre dos fuegos interpretativos? El propio Fernando Fuenzalida señalaría, en marzo de 1983, ante un auditorio atiborrado de estudiantes de la Facultad de Ciencias Sociales de la Universidad Católica, que el compromiso al que el antropólogo debía estar siempre dispuesto es a asumir la representación de estos campesinos cuando sea necesario: " $A$ ser la voz de estos campesinos que no tienen voz. A ser la presencia de estos campesinos que no tienen presencia en nuestro mundo que [...] se ha querido llamar el 'mundo oficial'” (1983b, p. 6). Por su parte, Rodrigo Montoya, al criticar duramente los argumentos de los asesores antropológicos de la comisión, concluye: "Para eso se sirve de la antropología, como elemento de análisis y decoración" (1983d, p. 7). En marzo de 1983, Montoya fue entrevistado por el diario La República. El periodista lo interpela acerca del papel de la antropología en estas circunstancias trágicas:

Periodista: Si José María Arguedas estuviera vivo y tuviera que ocuparse de la masacre de Uchuraccay, ¿qué piensa que hubiese dicho?

Rodrigo Montoya: Habría salido a la defensa de los campesinos inmediatamente, habría peleado, habría salido a declarar con toda razón en defensa de los comuneros. No es pretensión ni falsa modestia, pero la reacción que yo he tenido frente a esto, me viene inspirada directamente de él, ha sido mi maestro y he sido amigo de Arguedas [...] Lo que hice fue sentarme y escribir "los campesinos no son salvajes", porque ese es el deber de los antropólogos. (Montoya, 1983b, p. 8)

Cierra este cuadro un breve artículo del historiador Manuel Burga, publicado en el suplemento cultural de izquierda, El Caballo Rojo, con un título incontestable: "Uchuraccay: La antropología como justificación” (1983, p. 10).
Burga cuestiona en él ácidamente el Informe de la Comisión pues sus conclusiones representan un aval, aparentemente lógico y coherente, de los sucesos de Uchuraccay en base a cierto tipo de antropología andina: "campesinos que viven en otro mundo, con otra moral, otra sensibilidad frente al dolor" (Burga, 1983). Esto podría parecer normal en la imaginación etnográfica estructuralista, señala Burga, "pero es un disparate si se observa con una óptica diferente el caso Uchuraccay" (Burga, 1983, p. 11).

Pero la principal debilidad del Informe no descansaba necesariamente en su dudosa interpretación antropológica. Para Burga, el punto ciego de todo el trabajo radicaba en las superficiales condiciones de su producción etnográfica: "Los antropólogos [basaron] todo su informe en las cuatro horas -con un traductor- que pasaron en Uchuraccay" (1983, p. 11). Revelar este detalle era muy sensible. En una disciplina que hizo del trabajo de campo prolongado su marca y sello de identidad, no era posible, a ojos de Burga, que "ningún etnógrafo serio pueda escribir un informe científico con una visita de cuatro horas" (1983, p. 11). En tan corto tiempo, era improbable que funcionara la "magia del etnógrafo" (Stocking Jr, 1992). Burga concluye: "B. Malinowski habría reído ruidosamente ante un informe semejante" (1983, p. 11).

Pero estas disputas por la representación etnográfica no presagiaban lo que vendría poco después ${ }^{11}$. Lo peor para los comuneros de Uchuraccay aún estaba por llegar ${ }^{12}$. Durante los meses siguientes a la masacre de los periodistas, distintas columnas armadas de Sendero Luminoso incursionaron sucesivamente en la comunidad y asesinaron a quienes habrían tenido alguna participación en la muerte de los periodistas. Los ataques ocurrieron el 20 
de mayo, el 16 de julio y el 24 de diciembre de 1983. Todas las incursiones sucedieron en momentos festivos religiosos. La masacre del 20 de mayo ocurrió durante las fiestas del Espíritu Santo (Corpus Christi), y en ella murieron alrededor de 20 campesinos. El segundo ataque aconteció a la medianoche del 16 de julio, luego de concluida la fiesta de la Virgen del Carmen. Murieron 20 comuneros. El tercer ataque se dio en la víspera de la navidad, el 24 de diciembre, y en el se dio muerte a 8 comuneros.

Pero no solo fue Sendero Luminoso el que asesinaba campesinos. También las fuerzas armadas y los comités de autodefensa campesina incursionaron en la comunidad, entre 1983 y 1984 y mataron a decenas de campesinos, acusándolos de senderistas. Ante tantos ataques y muertes, finalmente, hacia agosto de 1984, a los comuneros de Uchuraccay no les quedó más opción que la de vivir esparcidos entre distintas comunidades vecinas, refugiarse en las ciudades de Huanta y Huamanga o, incluso, vivir como migrantes desplazados en Lima. La comunidad quedó totalmente deshabitada hacia fines de 1984. Las cifras finales son catastróficas. Durante los años del conflicto armado fueron asesinados 135 ciudadanos de Uchuraccay, en una comunidad que en 1981 tenía 470 habitantes (Comisión de la Verdad y Reconciliación, 2003, p. 146).

La tragedia en Uchuraccay puso en evidencia los límites del "paradigma andinista" para comprender las nuevas prácticas políticas y culturales de las poblaciones campesinas andinas. Estos sucesos demostraron ser la partida de defunción de aquella representación etnográfica -idealizada, estática y romántica-, tejida en decenas de monografías sobre "los indígenas" peruanos. Escrita por antropólogos lime- ños, ayacuchanos y extranjeros, esta versión exotizada del mundo andino no se percató de que los campesinos no solo estaban involucrados activamente, desde hacía mucho, en circuitos económicos de intercambio mercantil y en dinámicas de contacto fluido y flexible con la "modernidad"; sino, además, que habían resultado envueltos trágicamente, desde mayo de 1980 , en un cruento conflicto armado que azotaba distintas zonas rurales del Perú. No tuvo respuesta alguna para explicar cómo y por qué vastas zonas campesinas se habían convertido, en breve tiempo, en el teatro de operaciones de la guerra sostenida entre Sendero Luminoso, las fuerzas armadas y los propios campesinos.

\section{Desafiando la modernidad desde la "utopía andina"}

Hubo también otro camino seguido en el debate sobre lo "andino" y la modernidad en el Perú. Este discurrió en un carril paralelo al esencialismo andinista del Informe sobre Uchuraccay. Esta vez historiadores y antropólogos, ligados a los grupos y partidos de izquierda, discutieron sobre las posibles rutas culturales que tomarían las poblaciones andinas al enfrentarse a un proceso de conflictiva modernización capitalista de la sociedad rural.

Esta discusión se centró en el estudio de las mentalidades y la "utopía andina", cuyo argumento central ponía énfasis en la relación de resistencia y oposición entre los Andes (la cultura andina) y Occidente (modernidad capitalista), entendiendo ambos polos como bloques homogéneos y contrapuestos. Su principal expositor fue el destacado historiador marxista Alberto Flores Galindo quien, junto a un selecto 
colectivo de investigadores e intelectuales de izquierda, logró levantar la poderosa imagen histórica del Perú de los años ochenta como una sociedad que vivía una confrontación inevitable entre el mundo andino y el mundo occidental.

Alberto Flores Galindo impulsó, en 1987, la revista socialista Márgenes. Encuentro $y$ Debate, que congregó a un sector importante de intelectuales de izquierda, la gran mayoría de las ciencias sociales. En su primer editorial reclamaron su abierta filiación socialista y revolucionaria interpelando a los demás intelectuales de izquierda (la mayor parte, según ellos, estaba virando hacia posturas socialdemócratas) para definir una posición frente a la crisis de los años ochenta: “¿Cuánto hace que los intelectuales de izquierda dejaron de pensar en la utopía, en la estrategia, en la urgencia de un proyecto colectivo?" (Márgenes. Encuentro y Debate, 1987, p. 3). Preocupados por la distancia existente entre el pensamiento intelectual y la acción política, señalaban que no les interesaba ubicarse "cómodamente en el territorio oficial de lo académico, sino cuestionar la sociedad peruana y el proyecto socialista [...] desde una posición que apuesta sin ambages por la utopía revolucionaria" (1987, p. 4).

El núcleo que aglutinó Flores Galindo orbitó alrededor de un centro político-intelectual, SUR, Casa de Estudios del Socialismo, fundada en 1986. La traducción historiográfica de esta postura se plasmó en distintos ensayos, artículos y libros de Flores Galindo ${ }^{13}, y$, en especial, en los últimos capítulos de su influyente libro Buscando un inca: Identidad y utopía en los Andes ${ }^{14}$ (que ganó el premio Casa de las Américas de Cuba en 1986) y en el ensayo póstumo "La tradición autoritaria" (Flores Galindo, 2001).
¿Cómo surgió la noción de "utopía andina"? Un primer rastreo ${ }^{15}$ indica que Flores Galindo teje la idea muy temprano, en 1977, en torno a la noción de utopía en la rebelión de Túpac Amaru (Flores Galindo, 1977). Luego reaparece de forma algo más explícita en 1978 cuando trabaja con el historiador Manuel Burga en investigaciones históricas sobre el milenarismo y el mesianismo andino. Al poco tiempo escriben juntos, en 1979, un libro muy influyente en la historia social de inicios de los años ochenta: Apogeo y crisis de la república aristocrática (Burga \& Flores Galindo, 1979), que les permite acercarse a lo "andino" como el núcleo de la explicación de la historia republicana.

Al año siguiente publican una relectura del siglo XIX y XX enfocada en los movimientos sociales campesinos andinos (Burga \& Flores Galindo, 1980). Poco después, en 1981, Flores Galindo usa por primera vez la idea de "utopía andina" para discutir su relación con el socialismo en el Perú (Flores Galindo, 1981). Pero será en el marco de un proyecto auspiciado por la UNESCO, en ese mismo año, que financió una propuesta académica de colaboración a largo plazo sobre la "utopía andina", que Burga \& Flores Galindo empiezan a dar una forma más orgánica a su propuesta de investigación ${ }^{16}$. Flores Galindo recuerda que "[c]uando Manuel Burga y yo nos interesamos por el tema de la 'utopía andina', lo hicimos creyendo encontrar en este tema precisamente un elemento de continuidad en la historia peruana" (1988b, p. 241).

El primer resultado fue el artículo programático escrito a dos manos "La utopía andina: Ideología y lucha campesina en los Andes: Siglos XVI-XX", publicado en la revista Allpanchis (Flores Galindo \& Burga, 1983), donde cuestionan el historicismo criollo y plantean 
otra posibilidad de relatar el proceso de la historia peruana. Una historia, aseguran los autores, que restituya del "ostracismo al Inca Garcilaso de la Vega, en Montilla, hasta el suicidio de José María Arguedas, en 1969" (Burga, 2019, p. 8). Todo parecía indicar que ambos historiadores escribirían un libro conjunto sobre el itinerario de la utopía andina, pero finalmente el proyecto se tradujo, pocos años después, en la elaboración de dos interpretaciones distintas sobre el mismo proceso. Flores Galindo publica primero, Buscando un inca, en 1986; y Burga, dos años después, Nacimiento de una utopía: Muerte y resurrección en los Andes (1988) ${ }^{17}$.

¿Qué condiciones hicieron posible la recepción de este nuevo tipo de historia, más cercana al palpitar de las luchas populares y que sustrae al historiador de la soledad del archivo y la tranquilidad de la cátedra universitaria? Ciertamente, la visión del Perú que subyace en Buscando un inca es producida por la confluencia entre la investigación histórica y la cultura marxista en el esfuerzo por integrar "la historia de los humildes en el tramado de la historia peruana, en el señalamiento del papel de las ideas, de las emociones, de los sueños y de la religión, como fuerzas que impulsan el cambio en la sociedad" (Bonilla, 1990, p. 13).

Queda claro, entonces, que no era una historia aséptica que nacía de espaldas a los movimientos sociales. En un polémico ensayo sobre el estado de la historiografía en Perú, Heraclio Bonilla señalaba, en 1980, que las condiciones sociales para la escritura de la historia entraban a una nueva etapa de producción por la movilización política y el "propio desarrollo de la conciencia política de las masas populares", que "obligó a los científicos sociales no sólo a explorar las posibilidades de construcción de un futuro distinto [sino también] a la recuperación de un pasado tempranamente arrebatado" (1980, p. 17). Pero también, había aportado la iluminación de un marxismo "depurado de sus interpretaciones dogmáticas", que obligó a la historiografía a "interesarse por el estudio de los resortes fundamentales del cambio social" (Bonilla, 1980, p. 17).

Curiosamente, el Perú de esos años tenía un parecido a la coyuntura de los años veinte en el siguiente sentido: compartían las mismas dificultades para comprender las complejidades de un país atrapado en una profunda transformación cultural y en el impacto negativo dejado por sucesivas modernizaciones truncas. Precisamente, para advertir de esta complejidad, Flores Galindo publicó en 1980 una biografía intelectual de José Carlos Mariátegui, La agonía de Mariátegui. Allí colocó a Mariátegui ante los dilemas de la década de 1920, para lo cual reconstruyó el momento cultural de inicios del siglo $X X$, rescatando así la originalidad de un pensamiento cuya clave radicó en su convicción de que para que el socialismo y las ideas de Marx se convirtieran en una real alternativa revolucionaria en el Perú debían primero fusionarse con las tradiciones culturales e históricas del país:

Cualquier posibilidad exitosa del marxismo en el Perú pasaba por la confluencia con la cultura andina; por eso el profundo respeto de Mariátegui hacia Valcárcel, y su defensa de los indigenistas, no sólo contra algunos jóvenes intelectuales criollos proclives al leguiísmo, como Luis Alberto Sánchez, sino también en contra de algunos marxistas ortodoxos que despreciaban al mesianismo andino. (Flores Galindo, 1980, p. 49) 
Esto es, Occidente debía entroncarse con la "cultura andina" representada, en su esencia, por los campesinos indígenas. Sin los indígenas, la revolución socialista no era posible, dada la debilidad demográfica y estratégica de la clase obrera:

\begin{abstract}
El interés de Mariátegui por el mundo andino acabó comprendiendo tanto el presente como el pasado [...] Aunque fuera paradójico, en el mismo atraso de la sociedad peruana encontraba Mariátegui la exigencia y la justificación del socialismo [...] La revolución en el Perú, a diferencia de la república impuesta por los criollos, no debería hacerse contra el indio, a costa de nuestra personalidad nacional, sino que, por el contario, además de respetarla, debería mantenerla y fomentarla. (Flores Galindo, 1980, p. 47)
\end{abstract}

Al respecto, Aníbal Quijano señala dos pistas para ubicar mejor el contexto de producción de La agonía de Mariátegui y comprender las condiciones de su recepción. Por un lado, el debate en torno al eurocentrismo del "socialismo realmente existente y sus consecuencias a escala planetaria" y, por otro, "[la emergencia] de movimientos populares en gran parte de América Latina, en particular el caso peruano, desde mediados de los años setenta en adelante" (Quijano, 1990, p. 47). En efecto, el Perú de esa época, pese a todo, se modernizaba desordenadamente, la hacienda se resquebrajaba por efecto de la reforma agraria, se aceleraba la descampenización, se consolidaba la migración rural y crecían caóticamente las ciudades. La certidumbre dominante en el paradigma clasista de la izquierda señalaba que el escenario futuro de cualquier cambio solo podía estar en la ciudad.

Buscando un inca trata de buscar respuestas colectivas a esta crisis nacional, apelando al influjo de las tradiciones comunitarias. Flores
Galindo menciona: "En la actualidad, en la cultura andina coexisten tanto la esperanza en el progreso como la vuelta al pasado" (1989b, p. 15). En sus páginas rastrea el horizonte mental creado por los pueblos andinos a lo largo de varios siglos de dominación colonial y republicana: las utopías elaboradas como rechazo a un presente de opresión, ante el cual recrean el país de los incas como una sociedad alternativa, justa e igualitaria. "Utopia andina" es el término acuñado para referirse a ese universo mental que recorre, con desniveles, la historia andina peruana desde el siglo XVI hasta el cataclismo capitalista de fines del siglo XX. En ese sentido, para Manuel Burga, la "utopía andina" constituye también:

[...] una estructura estable de representaciones colectivas en Perú. Cada grupo social, cada sector de la sociedad hace su propia interpretación de esta utopía. Los campesinos indígenas la han convertido en 'Inkarri', los nobles rebeldes en el regreso del Tawantinsuyo, los políticos modernos en la prédica de una identidad cada vez más indígena del Perú y aún los técnicos actuales la traducen en programas de recuperación de técnicas, plantas y animales propios de las ecologías andinas. (Burga, 1988, p. VI)

En ese camino histórico, en Buscando un inca aparecen distintos personajes clave que pueden ser leídos de manera distinta: el Inca Garcilaso, Guamán Poma de Ayala, Túpac Amaru II, los indigenistas como Luis Valcárcel y José Carlos Mariátegui o creadores literarios como José María Arguedas. ¿Qué tenían en común? Pues que representaban la encarnación intelectual, por momentos obsesiva y otras veces trágica, del afán por domesticar y traducir las ideas occidentales a la realidad andina. La idea central era que pese a los múltiples cambios modernizadores en la historia peruana, aún prevalecían, en millones de campesinos, fuerzas ideo- 
lógicas milenaristas y mesiánicas ${ }^{18}$. Es decir, la misión letrada de la "utopía andina" era fusionar la razón (Occidente) con la pasión (la cultura andina). El libro de Flores Galindo se esfuerza "por acercar el español al quechua, la urbe a la comunidad, el marxismo a una visión de la revolución como inversión del mundo -como pachacuti-; visión que, en 1980 , se confunde con el maoísmo de Sendero Luminoso" (Rénique, 2010, p. 4). Pero, además, en Buscando un inca se encuentra "un punto de vista acerca del papel actual de la izquierda y de la revolución en el Perú" (Rénique, 1988, p. 144).

En sus páginas, Flores Galindo desarrolla la noción de "utopía andina", entendida como un elemento fundante de la identidad nacional y cuya representación de continuidad histórica puede aún observarse en el presente ${ }^{19}$. La propuesta tomó como base la revaloración de la "cultura andina", concebida a manera de modelo de desarrollo alternativo, y desde la cual era posible encontrar un camino inédito en el Perú: una invitación a pensar lo "andino" desde nuestro propio entorno. Pero este rescate de la "tradición", como sostendría en un polémico prólogo (Flores Galindo, 1989c), no descansaba en ninguna intención romántica, pasadista o neoindigenista, tampoco procuraba refugiarse en las cárceles de la "larga duración" y mucho menos buscaba huir del presente:

Al pensamiento de izquierda sí le debe interesar el pasado en la medida que no se deje arrastrar por la corriente de la transnacionalización de la cultura y se empeñe en encontrar una vía alternativa para el desarrollo del país. En ese sentido, una mirada crítica sobre la historia peruana conduce a cuestionar el derrotero que se le impuso a este país desde el siglo XVI. (Flores Galindo, 1989c, p. 20)
Por el contrario, en sus páginas nos ofrece una lectura muy particular del propio siglo $X X$. Sostiene que al finalizar aquel siglo, el edificio rígido y excluyente de la sociedad oligárquica sufre una grieta irreparable, cuyo desplome permite la constitución de una tupida red de actores y organizaciones sociales que logra modificar la conciencia social de los sectores populares:

El movimiento campesino primero, los movimientos obreros, estudiantil, de pobladores de barriadas, después, resquebrajan el edificio aparentemente tan sólido de la dominación oligárquica. La actual República trata de utilizar lo que queda de sus cimientos y paredes, pero es ya una edificación tan antigua e inoperante, como el vetusto Palacio Legislativo de la Plaza Bolívar. (Flores Galindo, 2001, p. 194)

En este escenario, lo "andino" deja de ser sinónimo exclusivo de términos como indígena, sierra, ruralidad y pobreza. ¿Qué aceleró esta tendencia? Las migraciones y el descenso masivo de los hombres andinos a la costa, un fenómeno sin precedentes que terminó por resquebrajar las jerarquías étnicas edificadas en la Colonia y continuadas en la República. "Ha terminado ocurriendo el vaticinio de Luis Valcárcel, pero sin sus rasgos apocalípticos. Estos hombres reclaman respuestas nuevas" (Flores Galindo, 1987, pp. 365-366).

Sin embargo, esta democratización que derivó, por ejemplo, en la democracia del sindicato, las asambleas comunales o de clubes de provincianos en Lima, no logró encontrar un correlato efectivo y una representación en la vida política nacional. A este proceso de ampliación democrática le faltaban vasos comunicantes que articularan al Estado y la sociedad. Pero la conclusión es aún más contundente: 
La ruptura entre Estado y sociedad es en realidad, la expresión política de un país donde las solidaridades son escasas, no existe una imagen común, ni se comparten proyectos colectivos. Ser peruano es una abstracción que se diluye en cualquier calle entre rostros contrapuestos y personas que caminan "abriéndose paso". (Flores Galindo, 2001, p. 189, subrayado del autor)

No era esta, por cierto, la interpretación solitaria de un historiador marxista recluido en la soledad de los archivos o en la solemnidad de la cátedra universitaria ${ }^{20}$. Al contrario, fue un sentido común compartido esos años por un amplio sector de intelectuales de izquierda que encontró en Flores Galindo a su más destacado exponente (Aguirre, 2007). Sin embargo, lo que aquí importa destacar es el modo en que Flores Galindo situó, en este escenario, a las poblaciones andinas. Desde su propuesta -la de cuestionar la historia desde el derrotero que se le impuso en siglo XVI- la "cultura andina" se encuentra amenazada por el avance arrollador de la modernización capitalista, que le impone límites para encontrar su propio modelo de desarrollo cultural y le impide al Perú convertirse definitivamente en "nación"21. La disyuntiva histórica es clara: o resisten o quedan relegadas a la supervivencia frente al avance irrefrenable de la modernidad capitalista:

\footnotetext{
El Perú de fines de los años ochenta vive en medio de un nuevo enfrentamiento entre el mundo andino y occidente que, en este caso, equivale a modernidad, capitalismo, progreso [...] Este desencuentro se produce en [...] un momento en el que la cultura andina aparece ubicada finalmente a la defensiva, en una situación precaria [...] por la tendencia a la "uniformización" que el mercado interno y el capitalismo buscan siempre imponer. (Flores Galindo, 1987b, p. 365)
}

No obstante, para comprender las coordenadas de estas lecturas hay que considerar un hecho crucial de las ciencias sociales de las décadas de 1970 y 1980: una vez cancelada la hacienda y el gamonalismo como formas de poder rural, las comunidades campesinas pasan a ocupar un mayor protagonismo en sus intereses de investigación. Buena parte de las ciencias sociales destinan, entonces, sus reflexiones a resaltar sus rasgos potenciales de solidaridad, horizontalidad y cooperación para enfrentar creativamente un conjunto de situaciones económicas y ecológicas adversas: aparece así la comunidad campesina como un reducto de resistencia a la modernización (Plaza \& Francke, 1981; Grillo, Oosterkamp, Coolman \& De Mezquita, 1988):

La utopía niega la modernidad y el progreso, la ilusión del desarrollo entendida como la occidentalización del país. Hasta ahora, el resultado ha sido la destrucción del mundo tradicional sin llegar a producir una sociedad desarrollada. No funcionó el modelo de una economía exportadora de materias primas. Parece demasiado tarde para ensayar el camino de Taiwán. Entonces, tal vez, sólo queda volver a mirar hacia el interior, en dirección al agro y los pueblos andinos. El desafío consiste en imaginar un modelo de desarrollo que no implique la postergación del campo y la ruina de los campesinos y que, por el contrario, permita conservar la pluralidad cultural del país. Recoger las técnicas tradicionales, los conocimientos astronómicos, el uso del agua [...] ¿Populismo? ¿Romanticismo? [...] El mito que reclamaba Mariátegui. (Flores Galindo, 1987b, p. 364)

La comunidad campesina pasó a constituir la principal institución que definía lo rural, como un espacio social distinto y la base de alternativas políticas más adecuadas a las necesidades y potencialidades de los 
campesinos (Monge, 1994). Este punto es especialmente importante por la referencia que otorga Flores Galindo a las comunidades campesinas, tema de reflexiones antropológicas durante décadas:

Después de una historia clandestina a lo largo del siglo XIX [las comunidades campesinas] volvieron a emerger en la vida política del país cuando en 1924 Leguía les devolvió el reconocimiento que se les había negado antes por la República [...] Hoy se calcula que es la institución más importante en la sociedad civil peruana. Ha logrado persistir no obstante el desarrollo del capitalismo y las migraciones. (Flores Galindo, 2001, p. 182 , subrayado del autor)

De forma notable en el debate de la década de 1980 reaparecen temas que ya los antropólogos habían superado, al menos en parte, dos décadas atrás: esto es, los límites a oponer tradición a modernidad, comunidad campesina a modernización capitalista, cultura andina a Occidente. Sorprendentemente, Manuel Burga, coautor con Flores Galindo de varios escritos sobre la "utopía andina", relaciona lo andino con lo no occidental:

Siempre que el mundo occidental ha fallado en el Perú, se ha mirado el mundo alternativo que es el andino, y en estos últimos años, especialmente en la última década cuando este mundo occidental ha fallado en sus propuestas y esquemas, es que nos vemos, sin darnos cuenta y empujados por fuerzas sociales, yendo hacia lo andino, tratando de entenderlo, rescatarlo, revalorizarlo. $Y$ no es solamente una actitud de los historiadores, sino es también la de otros científicos sociales como los antropólogos. Pero, aún podemos alejarnos un poco más, y llegar a los políticos y tecnólogos, que también miran con cierta curiosidad lo andino. [Lo andino] es la búsqueda de probables soluciones en lo no occidental (Burga, 1990, p. 53). (Énfasis del autor)
Pese a las advertencias del propio Flores Galindo de que su propuesta no buscaba enfrentar lo "andino" a la modernidad, sus afirmaciones son categóricas: "En realidad, tras el asunto de la modernidad se esconde un discurso de defensa de Occidente, el capitalismo y la civilización burguesa" (Flores Galindo, 1989c, p. 155). Y añade:

Las difíciles condiciones de vida y las peculiaridades de nuestra ecología determinaron que los campesinos, en medio de su pobreza, no pudieran incorporar tan fácilmente la modernidad de la tecnología de Occidente; y que por tanto conservaran ciertas formas de organización tradicional. Creo, entonces, que cultura andina y pobreza son dos fenómenos que han estado muy asociados en la historia peruana. (1989c, p. 140)

Pobreza y atraso parecen el punto de partida para pensar una modernidad alternativa. Flores Galindo reconoce que la discusión intelectual y política en torno a esta problemática puede facilitar el redescubrimiento en la propia historia de un nuevo tipo de modernidad, de rostro andino, que sería la que corresponde al Perú de los años ochenta:

En un país como el Perú se puede hacer algo más trascendente que abrir puertas y ventanas a la modernidad: someterla a una crítica, desde un espacio atrasado y marginal [los Andes], que ha debido soportar los costos de la modernización y que tiene tras de sí otras tradiciones culturales. (Flores Galindo, 1989c, p. 11)

Sin duda, la interpretación de Flores Galindo es variada y compleja. En su prosa se entremezclan la historia con el dato etnográfico, la literatura y las imágenes plásticas, la sociología con el psicoanálisis (Flores Galindo, 1987b). En ocasiones, sus afirmaciones resultan contradictorias, aunque revestidas por una poderosa 
trama metafórica y un robusto trasfondo argumental. Por ejemplo, cuando vincula el socialismo con la utopía: "un proyecto socialista utiliza cimientos, columnas y ladrillos de la antigua sociedad, junto con armazones nuevos" (Flores Galindo, 1986, p. 364); o cuando señala el momento agónico del redescubrimiento intelectual de lo "andino" en la década de 1980: "Esta preocupación nace en medio del conflicto entre la cultura andina y el mundo occidental, que se ha agudizado en los últimos años" (Flores Galindo, 1989b, p. 139).

Pero cuando se sumerge en la segunda mitad del siglo $X X$, sus conclusiones adquieren un tono pesimista, cuando no preñadas de cierto "fatalismo de las estructuras". Refiriéndose al impacto de Sendero Luminoso señala, en un balance sobre su generación de izquierda, que "el senderismo puso en evidencia la fragilidad de la imagen que del país se tenía al llegar 1980" (Flores Galindo, 1987a, p. 117), en una época "intensa en la producción de utopías en el espacio andino" (Flores Galindo, 1986b, p. 365). Pese al rudo dogmatismo de Sendero Luminoso, sus propuestas suenan menos disparatadas "si pensamos que fueron imaginadas en el interior de una región que fue el centro de un gran imperio prehispánico" (Flores Galindo, 1987b, p. 322). En 1988 afirmaba que el "autoritarismo senderista [...] recoge, como es evidente, elementos que están presentes en nuestra historia [...] de la que han salido la cólera, el odio y el resentimiento, que antes no veíamos o estaban demasiado ocultos" (Flores Galindo, 1988b, p. 17).
¿Se podía explicar el origen y el avance de Sendero Luminoso por la frustración política, el desarraigo y el resentimiento acumulado por siglos? En todo caso, la postura de Flores Galindo se torna algo ambigua cuando señala que Sendero Luminoso "parecía realizar la esperanza de Arguedas de transformar 'la rabia y la cólera individual en un odio colectivo, en un gran incendio'" (Flores Galindo, 1986b, p. 331). Pero el argumento adquiere un tono mucho más fatalista cuando subraya que "el autoritarismo senderista quiere ser una respuesta -la más radical posible-al racismo" (Flores Galindo, 1988b, p. 17).

Este ánimo pesimista es aún más relevante si consideramos que en los años ochenta se vivía una coyuntura de acelerados cambios políticos y emergían nuevos actores populares y movimientos sociales que pujaban por construir un claro "protagonismo popular" y ensanchar los espacios de democratización estatal en vías de construir un proyecto de ciudadanía "nacional-popular". Rescato un ejemplo de pesimismo, entre otros posibles:

[En el Perú] el margen para el consenso resulta estrecho. Para comprobarlo se puede recurrir, por ejemplo, a observar la distribución del espacio en Lima [...] No hay plaza pública, paseo o parque en los que confluyan personas de cualquier extracción social y de diverso origen étnico. En Lima predominan las exclusiones. Los burgueses buscan edificar otros centros de la ciudad porque los pobres han invadido la "vieja Lima" [...] Lima ha sido, desde Pizarro, la sede de la dominación: lo occidental y moderno imponiéndose sobre el mundo andino". (Flores Galindo, 2001, p. 189, subrayado del autor) 
Quizá la solución, desde su lectura, sea repensar la problemática de la modernidad y la democracia desde otra óptica: la de su encuentro con una revolución social de orientación socialista y raíces andinas, como sugiere en uno de sus ensayos:

[...] otro desenlace podría avizorarse si a la mística milenarista [andina] se añade el socialismo moderno con su capacidad de organizar, producir programas estratégicos y moverse en el corto plazo de la coyuntura política. En otras palabras, si la pasión se amalgama con el marxismo y su capacidad de razonamiento. (Flores Galindo, 1987b, p. 368)

En esta perspectiva, es comprensible la insistencia de esta corriente de historiadores y antropólogos (como Rodrigo Montoya, 2005, en La cultura quechua hoy, 1987) por encontrar las rutas que faciliten el encuentro entre la tradición socialista occidental y la tradición cultural andina. Por cierto, eran conscientes de que este empeño intelectual no significaba una completa novedad a la luz de los reiterados intentos indigenistas por representar al "indio" a lo largo del siglo XX. Así lo entiende Flores Galindo: "Este interés por el mundo andino tiene el riesgo de propiciar actitudes románticas o de añoranza del pasado y de confluir con el antiguo discurso indigenista de los años veinte". (Flores Galindo, 1989a, p. 147)

Incluso Rodrigo Montoya señalaría, en 1981: "me parece que estamos empezando a vivir un tercer indigenismo [...] que tiene que ver directamente con organizaciones políticas y con planteamientos que giran precisamente alrededor del 'problema nacional', de la necesidad de una 'izquierda nacional', de un proyecto nacional" (Montoya, 1981, p. 41). En 1988, el mismo
Montoya se preguntaba sobre la angustiada relación entre lo occidental y lo "andino":

Si no todo lo occidental es malo y no todo lo indio es bueno las preguntas de fondo que quedan son: ¿Qué guardar de occidente y a qué renunciar de lo indio? y ¿qué guardar de las sociedades indígenas y a qué renunciar de occidente? [...] Si no hay topes para detener esta tecnología [capitalista], para colocarla al servicio de la solidaridad entre los seres humanos, lo que nos espera es simplemente la desaparición de todo el saber indígena. Esa desaparición está en el extremo futuro del desarrollo capitalista de occidente que comenzó con Francisco Pizarro y Hernando Cortez. (1988, p. 23)

El fatalismo histórico en el diagnóstico del presente es constante. Es interesante resaltar que estos antropólogos e historiadores se sintieran herederos de una tradición intelectual que los conectaba ideológicamente con el proyecto del socialismo indígena de José Carlos Mariátegui, con la etapa del utopismo radical de Luis E. Valcárcel, con las propuestas literarias -y no tanto las etnográficas- de José María Arguedas ${ }^{22}$. ¿Eran estos autores los legítimos herederos del indigenismo? Aquí una pista, Flores Galindo señalaba: "Entre un intelectual y un campesino, tenía que existir un 'intermediario', éste era el indigenista" (Flores Galindo, 1987b, p. 271).

A fin de cuentas, el desafío intelectual era el de cómo conciliar, en un país rural y atrasado, el socialismo occidental con la "cultura andina". Hacia al final de Buscando un inca Flores Galindo señalaría: "El socialismo no sólo busca el cambio. Persigue algo que no estaba presente en la cosmovisión prehispánica: la edificación de un nuevo orden" (1987b, p. 245). Sin embargo, consciente de los 
malentendidos que surgieron con su libro más provocador, el mismo Flores Galindo anotaba en 1988 que "si bien la búsqueda de un inca ha obsesionado a muchos en el pasado peruano, no habría que seguir buscando un inca. El pasado es útil y necesario a condición que tengamos algún control sobre él y no permitamos que sus fantasmas nos cierren el horizonte" (1988b, p. 245).

Lo cierto es que la década de 1980 se cerraba con un cúmulo de publicaciones sobre el "mundo andino". Intentando explicar este torrente "andinista", el sociólogo Alberto Rocha hacía notar, en un artículo periodístico de 1989, que se estaba ante la presencia de una nueva forma de pensar el Perú republicano desde el Perú profundo "ya no como antes sino como corriente 'neo-indigenista' [...] al menos en el campo de la izquierda y del socialismo. Estamos ante un alentador reencuentro de la intelligentsia con la fuerte presencia (¿emergencia?) del mundo andino en el Perú" (p. 21).

\section{Conclusiones}

En medio de la crisis de la década de 1980, la antropología fue la disciplina social más afectada porque su ideología, su ámbito de estudio, su rito de pasaje metodológico y su misión desarrollista quedaron desfasados. La manifestación de la crisis del "paradigma andinista" tuvo incluso lugar y fecha precisa: el Informe de Vargas Llosa de 1983 que buscó explicar la masacre de ocho periodistas ocurrida en la comunidad campesina de Uchuraccay en los primeros años del conflicto armado interno. Este informe se basó principalmente en la asesoría de cuatro antropólogos e hizo suyo el "paradigma andinista". Su tesis central demostró ser un obstáculo para superar aquella visión anacrónica de las comunidades campesinas, vistas casi como un reducto cultural no occidental, un lugar etnográfico distante del tiempo de la modernidad.

En muchas etnografías sobre los Andes prevalecieron perspectivas teóricas y metodológicas que privilegiaron la estabilidad de los sistemas sociales por encima de los incesantes cambios sociales, culturales y políticos de las poblaciones campesinas. El énfasis en las continuidades culturales del siglo $\mathrm{XVI}$ al $\mathrm{XX}$ como rasgos centrales de la fortaleza de la cultura andina resultó en una esencialización que se conoció como lo andino, entendida como una entidad cultural opuesta a la lógica histórica de Occidente, como se expresó en la propuesta de la "utopía andina" de Alberto Flores Galindo. No se realizó el necesario diálogo con las etnografías que se interesaron por la ampliación de la economía de mercado y la expansión capitalista en la sociedad rural. La consecuencia más directa fue el despojo de todo rastro de historicidad en las culturas estudiadas, recurriendo para ello al uso del presente etnográfico como estrategia estilística de representación discursiva. 


\section{Notas}

${ }^{1}$ Esto se observa más claramente en la obra de Carlos Sempat Assadourian. Para una discusión, véase Stern (1985).

${ }^{2}$ Para una discusión de estas perspectivas, véase Roseberry (1995).

${ }^{3}$ Brooke Larson se refiere a la conferencia "Andean kinship and mariage" realizada en Toronto en 1972, en el marco de la reunión de la Asociación Americana de Antropología, y publicada como Bolton \& Mayer (1977). Y también al simposio sobre Modos de Producción en América Latina, organizado y coordinado por Roger Bartra y Pierre Vilar. Este simposio se realizó en México durante el Congreso Internacional de Americanistas de 1974. Véase Bartra (1975). Ver, además, para un contexto más amplio, Larson (1995).

${ }^{4}$ Las investigaciones "andinistas" que se desarrollan desde la década de 1970 toman un giro explícitamente interdisciplinario (arqueología, historia, antropología). La preocupación central era el estudio de la producción de relaciones de resistencia y adaptación indígenas frente al poder estatal colonial y republicano. En esta convergencia interdisciplinaria destacan John Murra, James Lockhart, Nathan Wachtel y Karen Spalding, que recurren a la relectura de distintas fuentes etnográficas indígenas y españolas y al entrecruzamiento de diferentes posturas teóricas, que van desde el culturalismo hasta el estructuralismo. Véase Murra (1975), Lockhart (1968), Wachtel (1971) y Spalding (1974).

${ }^{5}$ Sin querer agotar nombres y propuestas, los más destacados son: Pablo Macera, Luis Lumbreras, Alfredo Torero, Manuel Burga, Nelson Manrique, Alberto Flores Galindo y Wilfredo Kapsoli. Como muestra de las sensibilidades historiográficas de ese momento es necesario revisar las importantes entrevistas del periodista Carlos Arroyo (1989).

${ }^{6}$ Sobre la ubicación e importancia de Uchuraccay, glosamos la siguiente explicación de la Comisión de la Verdad y Reconciliación: "Ubicadas a más de 3.800 msnm, las punas de Uchuraccay eran una zona de frontera entre la selva y los valles de Huanta y Tambo. Una zona estratégica para el PCP Sendero Luminoso, que consideró dicho territorio como corredor para incursionar en esos valles desde el Rasuwilca, nevado y apu tutelar más importante del norte de Ayacucho que los miembros del PCP SL convirtieron en base de operaciones" (Comisión de la Verdad y Reconciliación, 2003, p. 123).

${ }^{7}$ Además de Fernando de Tragzenies (jurista), Rodolfo Cerrón Palomino (lingüista) y Clodoaldo Soto Ruiz (lingüista).

${ }^{8} \mathrm{Al}$ respecto, véanse las críticas de Mayer (1991).

${ }_{9}^{9}$ Sobre las sucesivas intervenciones periodísticas de Rodrigo Montoya, pueden verse Montoya (1983c, 1983e, 1983f, 1983g, 1983h, 1983i, 1984a, 1987) y Ossio y Montoya (1983).

${ }^{10}$ En esa misma dirección, el historiador Pablo Macera declararía:
"De estas ocho muertes, somos responsables todos" (1983a, p. 14).

${ }^{11}$ Las intervenciones de antropólogos, historiadores y hasta de un arqueólogo serán constantes en la prensa de izquierda. Véase: Vega (1983), Degregori y Urrutia (1983), Burga (1984), Lumbreras (1983a, 1983b, 1984) y Macera (1983b).

${ }^{12}$ Aquí seguimos la información indicada en el Informe elaborado por la Comisión de la Verdad y Reconciliación sobre el caso Uchuraccay (2003, pp. 142-146).

${ }^{13}$ La participación de Flores Galindo en distintas publicaciones de izquierda es variada. De acuerdo al recuento hecho por Carlos Aguirre se observa que "fue editor en 1978 de la revista Vaca Sagrada junto con poetas como Marco Martos y José Watanabe; dirigió luego la revista Allpanchis del Instituto de Pastoral Andina entre 1978 y 1982; colaboró regularmente en el suplemento El Caballo Rojo entre 1981 y 1985; participó en varias publicaciones culturales de izquierda, como El Búho, 30 Días o El Zorro de Abajo; formó parte del comité editorial de la Revista Andina desde su creación en 1983; y, finalmente, fundó en 1987 'SUR. Casa de Estudios del Socialismo' y dirigió la revista Márgenes hasta su muerte en 1990" (2007, 171).

${ }^{14}$ Este libro ha tenido varias ediciones. Usaremos aquí la editada en 1987 por el Instituto de Apoyo Agrario (Flores Galindo, 1987b).

${ }^{15}$ Aquí seguimos las notas de Carlos Aguirre y Charles Walker (2010, p. XXI).

${ }^{16}$ En ese contexto, ambos historiadores insisten en elaborar una agenda que responda a la necesidad de construir un nuevo rostro, más andino y nacional, de nuestra historia, cuando polemizan, en 1981, con el historiador Heraclio Bonilla acerca de las tendencias historiográficas de la historia peruana. Véase: Bonilla (1980, 1981), Burga (1981),

${ }^{17}$ La primera edición del libro de Flores Galindo fue publicada por la editorial cubana Casa de las Américas (Flores Galindo, 1986b). La primera edición del libro de Burga salió en 1988.

${ }^{18}$ Por ejemplo, se puede ver esta perspectiva en Burga (1986).

${ }^{19}$ Asimismo, puede revisarse Saignes (1990) y Manrique (1988) para lecturas críticas de la utopía andina como propuesta historiográfica.

${ }^{20}$ De hecho, era profesor en la especialidad de sociología de la Facultad de Ciencias Sociales de la Pontificia Universidad Católica.

${ }^{21}$ Entre otros investigadores que siguen las líneas de esta discusión, aunque con matices, se encuentran Manuel Burga, Rodrigo Montoya, Nelson Manrique y Pablo Macera. Sobre el contexto intelectual del libro Buscando un inca y sus propuestas véase Rénique (1988).

${ }^{22}$ De hecho, Flores Galindo dejó inconclusa una biografía de José María Arguedas, de la cual solo conocemos dos breves ensayos (Flores Galindo, 1992). 


\section{Referencias bibliográficas}

Aguirre, C. (2007). Cultura política de izquierda y cultura impresa en el Perú contemporáneo (1968-1990): Alberto Flores-Galindo y la formación de un intelectual público. Histórica, 31, 171-204.

Aguirre, C. \& Walker, C. (2010). Introduction. En Flores Galindo, F., In search of an Inca: Identity and utopia in the Andes. Cambridge: Cambridge University Press.

Arroyo, C. (1989). Encuentros: Historia y movimientos sociales en el Perú. Lima: Memoria Angosta.

Bartra, R. (ed.) (1975). Modos de producción en América Latina. Revista Latinoamericana de Pensamiento Marxista, Historia y Sociedad, 5, Segunda época, 20-36.

Bolton, R. \& Mayer, E. (eds.) (1977). Andean kinship and marriage. Washington: American Anthropological Association.

Bonilla, H. (1980). El nuevo perfil de la historia del Perú. La Revista, 3, 11-18.

(1981). Algo más sobre el perfil de la historia peruana. La Revista, 5, 61-63.

(1990). Homenaje a Alberto Flores Galindo. En Presencia y aporte de Alberto Flores Galindo. Homenaje (p. 13). Lima: Facultad de Ciencias Sociales, Pontificia Universidad Católica del Perú.

Burga, M. (1981). Por una historia andina y nacional. La Revista, $5,59-60$.

(1983). Uchuraccay: La antropología como justificación. El Caballo Rojo, 182, 10.

(1984). Uchucraccay, un perfil de lo andino. 30 Días, 19 de febrero.

(1986). Los profetas de la rebelión, 1920-1923. En Dealer, J. P. \& Saint-Geours, Y. (Eds.), Estados y naciones en los Andes. Lima: Instituto de Estudios Peruanos.

(1988). Nacimiento de una utopía: Muerte y resurrección de los Incas. Lima: Instituto de Apoyo Agrario.

(1990). Mesa redonda: La Utopía Andina (Manuel Burga, Wilfredo Kapsoli, Alberto Flores Galindo, Juan Martínez Allier). Utopía. Revista de Política y Cultura, 1(1), 53.

(2019). Homenaje: Alberto Flores Galindo es recordado por el historiador Manuel Burga. El Comercio, 28 de mayo.

Burga, M. \& Flores Galindo, M. (1979). Apogeo y crisis de la república aristocrática. Lima: Rikchay Perú.

(1980). Feudalismo andino y movimientos sociales (18661965). En Historia del Perú, tomo XI. Lima: Mejía Baca.

Comisión de la Verdad y Reconciliación (2003). Caso Uchuraccay. En Informe Final, Tomo V. Lima: Comisión de la Verdad y Reconciliación.

De Trazegnies, F. (1983). Informe sobre Uchuraccay. En Informe de la Comisión Investigadora de los Sucesos de Uchuraccay. Lima: Editora Perú.

Degregori, C. \& Urrutia, J. (1983). Reflexiones sobre ocho muertes peruanas. El Diario de Marka, 6 de febrero.

Flores Galindo, A. (1977). La nación como utopía: Túpac Amaru
1780. Debates en Sociología, 1(1), 139-157.

(1980). La agonía de Mariátegui: La polémica con la Komintern. Lima: DESCO.

(1981). Utopía andina y socialismo. Cultura Popular, 2.

(1986). Buscando un inca: identidad y utopía en los Andes.

La Habana: Casa de las Américas.

(1987a). Generación del 68: ilusión o realidad. Márgenes.

Encuentro y Debate, 1, 117.

(1987b). Buscando un inca: Identidad y utopía en los

Andes. Lima: Instituto de Apoyo Agrario.

(1988a). Introducción. En Flores Galindo, A., Tiempo de plagas. Lima: El Caballo Rojo.

(1988b). La utopía andina: Esperanza y proyecto. En Flores

Galindo, A., Tiempo de plagas (pp. 248-254). Lima: El Caballo Rojo. (1989a). Lo andino en la encrucijada. Conversatorio:

Manuel Burga, Alberto Flores Galindo y Rodrigo Montoya. En Arroyo, C. (Ed.), Encuentros: Historia y movimientos sociales en el Perú. Lima: Memoria Angosta.

(1989b). El redescubrimiento de lo andino. En Arroyo,

C. (Ed.), Encuentros. Historia y movimientos sociales en el Perú. Lima: Memoria Angosta.

(1989c). Prólogo: El rescate de la tradición. En Arroyo,

C. (Ed.), Encuentros: Historia y movimientos sociales en el Perú. Lima: Memoria Angosta.

(1992). Dos ensayos sobre José María Arguedas. Lima: Casa de Estudios por el Socialismo.

(2001). La tradición autoritaria: Violencia y democracia en el Perú. En Flores Galindo, A., Los rostros de la plebe (pp. 165194). Barcelona: Crítica.

Flores Galindo, A. \& Burga, M. (1983). La utopía andina: Ideología y lucha campesina en los Andes: Siglos XVI-XX. Allpanchis, 20, 85-101.

Fuenzalida, F. (1983a). Uchuraccay: Comunidad campesina y una guerra ajena. El Comercio, 6 de febrero.

(1983b). Tratar de ser un poquito la voz de ese campesino sin voz. Ccantu, 6, 6 .

Grillo, E., Oosterkamp, F., Coolman, J. \& Mezquita, B. de (1988). Agua y agricultura andina. Lima: Consejo Andino de Manejo Ecológico, Proyecto de Tecnologías Campesinas.

Harris, O., Larson, B. \& Tandeter, E. (1987). Introducción. En Harris, O., Larson, B. \& Tandeter, E. (Eds.), La participación indígena en los mercados sudamericanos: Estrategias de reproducción social: Siglos XVI-XX. La Paz: CERES.

Larson, B. (1995). Andean communities, political cultures, and markets: The changing contours of a field. En Larson, B., Harris, O. \& Tandeter, E. (Comps.), Ethnicity, markets, and migration in the Andes (pp. 5-54). Duke: Duke University Press.

Larson, B. (2000). Cochabamba: [Re]construcción de una historia. La Paz: Plural. 
Lockhart, J. (1968). Spanish Perú, 1532-1560: A colonial society. Wisconsin: University of Wisconsin Press.

Lumbreras, L. (1983a). Entrevista Luis Lumbreras: Comunidades: ¿Lucha o muerte?, La República, 6 de marzo.

(1983b). Declara el Dr. Luís Guillermo Lumbreras: Informe de Uchuraccay descriptivo e incompleto. El Observador, 19 de marzo. (1984). Así es Uchuraccay. El Caballo Rojo, 193, 22 de enero.

Macera, P. (1983a). Todos somos responsables. El Observador, 7 de febrero.

(1983b). Entrevista al Dr. Pablo Macera: Uchuraccay, ¿crímenes sin castigo? La República, 19 de marzo.

(1977). Explicaciones. En Macera, P., Trabajos de historia (Tomo I). Lima: Instituto Nacional de Cultura.

Manrique, N. (1988). Historia y utopía en los Andes. Debates en Sociología, 12-14, 201-211.

Márgenes. Encuentro y Debate (1987). Editorial. Márgenes. Encuentro y Debate, 1(1), 3.

Mayer, E. (1991). Peru in deep trouble: Mario Vargas Llosa's "Inquest in the Andes" reexamined. Cultural Anthropology, 6(4), 466-504.

Monge, C. (1994). Transformaciones en la sociedad rural. En Dancourt, O., Mayer, E. \& Monge, C. (Eds.), Perú: El problema agrario en debate (pp. 33-77). Lima: Seminario Permanente de Investigación Agraria.

Montoya, R. (1981). Problema nacional, cultura y clases sociales. Lima: DESCO.

(1983a). Uchuraccay: Dos preguntas esenciales. La República, 14 de febrero, 14.

(1983b). Investigación se politizó. La República, 11 de marzo.

(1983c). Estado, tenientes, gobernadores y campesinos. La República, 17 de marzo.

(1983d). Entrevista al Dr. Rodrigo Montoya: Uchuraccay: ¿Crimen sin castigo? La República, 19 de marzo.

(1983e). Perú oficial y Perú real: la trampa de la apariencia. La República, 12 de abril.

(1983f). ¿Guerra civil en Ayacucho? La República, 23 de abril. (1983g). Uchuraccay: La comisión oficial y sus castillos

en el aire. La República, 30 de mayo.

(1983h). Cuestionando a propósito de Uchuraccay,

Ccantu, 6, 6 de septiembre.

(1984a). Pese a todos sabremos la verdad. La República, 26 de enero.

(1984b). A propósito de Trazegnies: No podemos olvidar Uchuraccay. La República, 30 de noviembre. (1987). Uchuraccay: Cuatro años después. La República, 15 de febrero.

(1988). El principio del peque peque. La República, 3 de marzo.

(2005). De la utopía andina al socialismo mágico (Antropología, historia y política en el Perú). Cusco: Instituto Nacional de Cultura.

Murra, J. (1975). Formaciones económicas y políticas del mundo andino. Lima: Instituto de Estudios Peruanos.

Ossio, J. \& Fuenzalida, F. (1983). Informe antropológico. La comunidad de Uchuraccay la región lquichana. Informe de la Comisión Investigadora de los Sucesos de Uchuraccay. Lima: Editora Perú.

Ossio, J. \& Montoya, R. (1983). Conversatorio: Uchuraccay: ¿Crimen sin castigo? La República, 19 de marzo.

Plaza, O. \& Francke, M. (1981). Formas de dominio, economía y comunidades campesinas. Lima: Centro de Estudios y Promoción del Desarrollo.

Quijano, A. (1990). La presencia polémica de Alberto Flores Galindo: Conversatorio con Franklin Pease y Aníbal Quijano. Pretextos, 1, 47.

Rénique, J. (1988). 'La utopía andina' hoy (un comentario a 'Buscando un Inca'). Debate Agrario. Análisis y Alternativas, 2. (2010). Flores Galindo y Vargas Llosa: Un debate ficticio sobre utopías reales. Herramienta, 45, 4.

Rocha, A. (1989). Presencia del mundo andino en el Perú. La República, 24 de julio.

Roseberry, W. (1995). Latin American peasant studies in a 'postcolonial' era. Journal of Latin American Anthropology, 1(1),150-177.

Saignes, T. (1990). ¿Es posible una historia 'chola' del Perú? (Acerca de 'Nacimiento de una utopía' de Manuel Burga). Allpanchis, 35-36, 635-658.

Salomon, F. (1982). Andean ethnology in the 1970s: A retrospective. Latin American Research Review, 17, 75-128.

(1991). Tres enfoques cardinales en los actuales estudios andinos. En Moreno, S. \& Salomon, F. (Comps.), Reproducción y transformación de las sociedades andinas, siglos XVI-XX (Tomo II). Quito: Abya Yala, Movimiento Laicos para América Latina.

Stern, S. (1985). New directions in Andean economic history: A critical dialogue with Carlos Sempat Assadourian. Latin American Perspectives, 12, 133-148.

Stocking Jr, G. (1992). The ethnographer's magic and other essays in the history of anthropology. Madison: University of Wisconsin Press.

Spalding, K. (1974). De indio a campesino: Cambios en la estructura social del Perú colonial. Lima: Instituto de Estudios Peruanos.

Thurner, M. (1998). Después de la etnohistoria: Encuentros y desencuentros entre discurso antropológicos e históricos. Actas del IV Congreso Internacional de Etnohistoria, Lima 1997 (Tomo II, pp. 459-485). Lima: Pontificia Universidad Católica del Perú.

Vargas Llosa, M. (1983a). Después del informe: Conversación sobre Uchuraccay: Entrevista a Mario Vargas Llosa realizada por Alberto Bonilla. Caretas, 738, 7 de marzo. (1983b). Informe sobre Uchuraccay. En Informe de la Comisión Investigadora de los sucesos de Uchuraccay (pp. 34-35). Lima: Editora Perú.

Vega, J. (1983). Uchuraccay, proceso al Perú. La República, 6 de marzo.

Wachtel, N. (1971). Los vencidos: Los indios del Perú frente a la conquista española. Madrid: Alianza. 